\title{
3D HOLISTIC DOCUMENTATION OF HERITAGE MONUMENTS IN RHODES
}

\author{
S. Tapinaki, M. Skamantzari, A. Anastasiou, S. Koutros, E. Syrokou, A. Georgopoulos* \\ Laboratory of Photogrammetry, School of Rural, Surveying and Geoinformatics Engineering, National Technical University of \\ Athens, Greece \\ tapinaki@central.ntua.gr,mskamantz@central.ntua.gr, anastasia1808@gmail.com, stratiskoutros@hotmail.com, \\ syrokoulena@gmail.com,drag@central.ntua.gr
}

KEY WORDS: Geometric Documentation, 3D Reconstruction, Image based modelling, Laser scanning, Cultural Heritage.

\begin{abstract}
:
This paper focuses on the holistic 3D geometric documentation of four Cultural Heritage buildings, of different historic eras, on the island of Rhodes. The main scope was to produce the 3D models and all required products according to the needs and specifications set by the EU funded HYPERION project. The ideal combination of multi-source data acquisition and processing was employed, which is the modern perception for the methodology of geometric documentation of monuments. The workflow for the combination of geodetic, photogrammetric and laser scanning data acquisition methods is described in detail. Very decisive factor in carrying out fieldwork for data acquisition was the time frame, which was very limited due to the COVID-19 pandemic. The establishing of a holistic framework for the documentation of Cultural Heritage by carrying out a wide range of multidisciplinary research, acquiring and combining datasets from various sensors and sources, as well as by developing innovative tools for systematic monitoring gives substantial results in order to protect, preserve and enhance Cultural Heritage sites. The documentation results are presented and discussed for their usefulness for the project.
\end{abstract}

\section{INTRODUCTION}

Cultural Heritage is a domain which has been and still is greatly affected by climate change. This adverse condition has become even worse in the recent decades. At the same time Information and Communication Technologies (ICT) have been greatly exploited to contribute to the holistic documentation, to support conservation and preservation actions (Kotoula and Georgopoulos 2015, Georgopoulos et al. 2018).

Towards this direction, European Union has decided to fund a relevant 4-year research project (Grant Agreement no 821054, Start date: 1st of June, 2019) entitled HYPERION: Development of a Decision Support System for Improved Resilience \& Sustainable Reconstruction of historic areas to cope with Climate Change \& Extreme Events based on Novel Sensors and Modelling Tools (https://www.hyperion-project.eu/). In HYPERION project resilience offers an overarching strategy that includes risk management, protection and preparedness as complementary strategies to prevent damages to cultural sites, identify and ward off additional threats and promote adaptation, reconstruction and other post-disruption strategies to restore normal conditions to the historic area, as well as long-term strategic approaches to adapt to Climate Change and to wield policy tools for economic resilience. Existing tools and services (e.g., climate/extreme events models, and their impacts, decay models of building materials, Copernicus services, etc.) and novel technologies (terrestrial and satellite imaging for wide-area inspection, advanced machine learning, etc.) will be leveraged to deliver an integrated resilience assessment platform (HRAP), addressing multi-hazard risk understanding, better preparedness, faster, adapted and efficient response, and sustainable reconstruction of historic areas. HYPERION is already performing extensive tests in four cultural heritage study areas, demo sites, within Europe, in Greece (Rhodes), Spain (Granada), Norway (Tønsberg) and Italy (Venice).
This paper focuses on the holistic 3D geometric documentation of four Cultural Heritage buildings on the island of Rhodes for the fulfilment of the research project requirements (Figure 1). These monuments belong to different historical eras. A Hellenistic burial complex in Rhodini park, a Roman bridge, which is still in use for heavy modern traffic today and two Medieval buildings, namely the Naillac Pier and the Saint Nikolaos Fort and lighthouse.

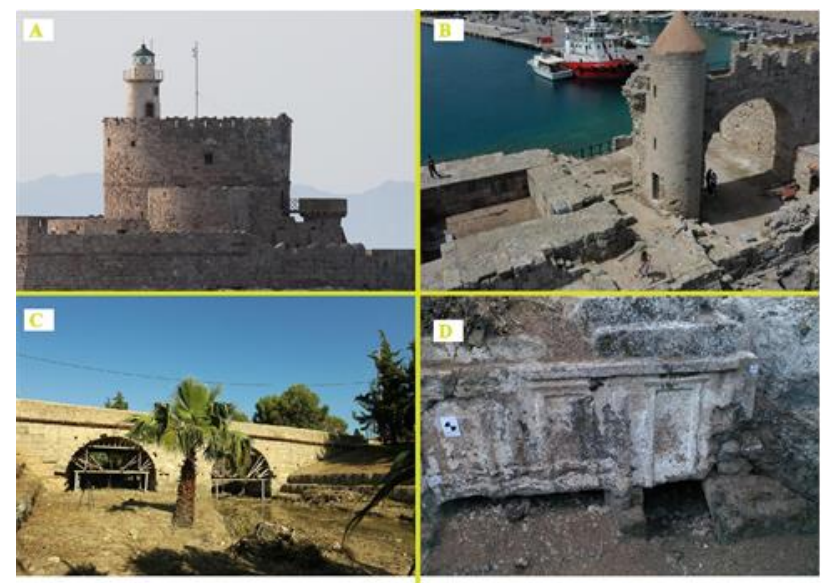

Figure 1. The four study areas in Rhodes.

The city of Rhodes (Figure 2) has a history of 2400 years and the different people who settled in during all these years left their mark on the island leading today to this cultural and architectural diversity. The four study areas are just some examples of the island's cultural wealth. 


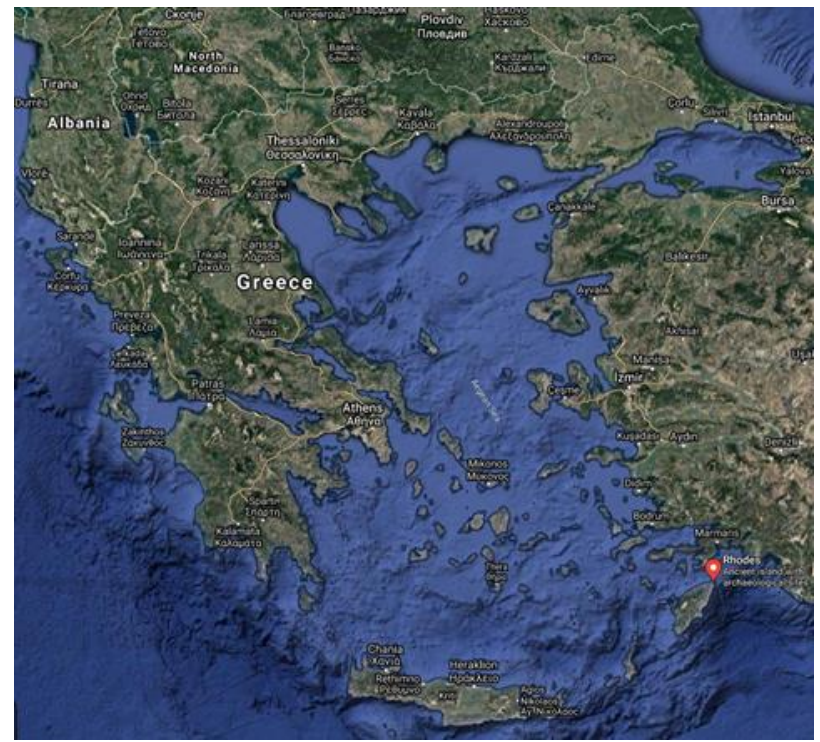

Figure 2. Map of Greece and Rhodes.

The Saint Nikolaos Fort and Lighthouse (Figure 1A) is an important part of the great fortifications of the Medieval City of Rhodes located at the entrance of the Mantraki port (HYPERION Deliverable 2.1,2020). At this location, there was just a chapel dedicated to Saint Nikolaos until 1464, when it was turned to a fortification by the Great Magister Zacosta. Since then it has undergone reinforcements and expansions in order to defend the city. The outer walls were built in $1480 \mathrm{AD}$ and in $1863 \mathrm{AD}$ it was finally transformed to a lighthouse.

The second study area is the Naillac Pier (Figure 1B) at Saint Paul's rampart where a monumental tower was located as part of the fortification of the Commercial Harbour of Rhodes, known as the "Great Port". It was constructed around 1400 AD on the Hellenistic Pier, but it was destroyed in 1863 after a severe earthquake. In 2017, the Naillac Tower was graphically reconstructed and presented as it stood until 1863, during the Ottoman rule (Manousou Ntella, 2017).

The Roman Bridge (Figure 1C) is one of the few ancient bridges surviving in Greece and part of the Hellenistic fortification of the city, making it a monument of great importance. It was built across the stream of Rhodini, situated outside the Medieval City and has two arched openings. The Roman Bridge is in continuous use until today and its static efficiency has deteriorated, while the scaffoldings which now support the arches are gradually rusting and losing their efficiency.

The last study area is the monumental Grave Enclosures in Rhodini Park (Figure 1D), the central necropolis of antiquity. The graves are dated in the Hellenistic period, in the 3rd-2nd century $\mathrm{BC}$ and they are hewn on the high rocks' facades, formed as enclosures and open to the stream. The environmental conditions and the microclimate in combination with natural disastrous events have caused severe damages to the tombs.

These four monuments in Rhodes were chosen and proposed as case studies for the HYPERION project by the Ephorate of the Antiquities of Dodecanese and the Municipality of Rhodes, both of which are partners of HYPERION. These monuments present obvious deteriorations due to weather conditions in many ways. The Saint Nikolaos Fort and the Naillac Pier are damaged by the exposure to the sea front, while the Rhodini bridge is suffering degradation mainly due to the humidity of the stream and, finally, the Grave enclosure is degrading due to the climate conditions in the Rhodini park.

\section{METHODOLOGY}

For the needs of the HYPERION project, 3D models of the study monuments were specified. Based on these 3D models, studies for deploying specific sensors for monitoring climate conditions and assessing the damage, in case of a disastrous event, were to be performed and later realized for pilot implementation. Hence, detailed 3D documentation was required.

A holistic approach has been implemented for the geometric documentation of the Cultural Heritage buildings, based on the extensive experience of the Laboratory of Photogrammetry of NTUA (http://digiphotolab.survey.ntua.gr/). The Laboratory has gained extensive experience through research and educational work, by participating in various projects related to cultural heritage objects that require three-dimensional geometric documentation. These projects are characterized by the required interdisciplinarity. The studies of various experts are based on data and information of the current state of the objects presented in different ways, depending on every expert's needs. The geometric documentation must be done in such a way that it meets the needs of all involved while, most of the time, the adaptation of procedures and methods is required due to the particularity of each project and object.

This holistic methodology was implemented for the geometric documentation of the church of St Spyridon in Rhodes as it is described by Anastasiou et al. (2020). The emblematic project of the rehabilitation of the Holy Aedicule in Jerusalem is worth mentioning, It has been a highly interdisciplinary project which required the documentation of each phase of the restoration works, in a very short time and the production of different products for different purposes each time, while at the same time monitoring of the Holy Aedicule during the interventions was mandatory (Moropoulou et al., 2017). Another research study for the Acropolis of Erimokastro, an archaeological site in Rhodes Island, required 3D geometric documentation for analyzing ancient walls within a particular environment and the integration of infrared thermography on the remaining walls of the archaeological site for its sustainable rehabilitation in the future (Tsilimantou et al., 2019). Less demanding but equally important are the projects for the restoration of the western part of the Castle of Chios and the Gate of the Cannons in Rhodes, where, besides the traditional products, the development of curved surfaces were also required (Georgopoulos et al. 2020). Noteworthy is also the reconstruction of the Plaka bridge, a monument declared under protection by the Greek State, situated in the Epirus region in northwestern Greece which collapsed due to massive floods. A restoration project was initiated by NTUA, immediately after the collapse, aiming to investigate all scientific aspects needed for the reconstruction of the monument. The state of the remaining parts of the bridge, after the collapse, was documented with both conventional on-site survey methods and image-based techniques and at the same time crowdsourced images were used for the construction of the 3D model of the south façade of the bridge, before the collapse (Stathopoulou et al. 2015). The geometric, architectural and structural data acquisition, process and analysis were treated separately in two study stages: before and after the collapse (Kouimtzoglou et al. 2017). Last but not least, the model study of all the technological parameters of the French Mines Wharf in Lavrion should be referenced. The French Wharf is a Heritage at Risk object and was integrated into the broader network of Lavreotiki and the Aegean mines to which 
it belongs. The research involved experts in the fields of static integrity, anti-seismic research, urban planning, construction, monument restoration, photogrammetry, metal structures, soil engineering and electromechanics. The challenge in this project was the materials and the complexity of the mines wharf that required special adaptation of all methods (Google Arts \& Culture).

For the 3D documentation and high-resolution representation of the cultural heritage buildings the combination of geodetic, photogrammetric and laser scanning data acquisition and processing methods have been applied, which is the modern perception for the methodology of geometric documentation of monuments and the best way of high precision fully controlled object documentation. Manual measurements should be included in these methods, where necessary. The methods of hand measurements, for example using tactile instruments, are auxiliary but also very important. Usually, they are used for checking the accuracy of the products but could be very important in cases where the other methods fail to acquire data. A similar approach for the fusion of full resolution threedimensional data streams generated from laser scanning, ground based photogrammetry and drone-based photogrammetry is described in Hess et al. (2015).

The main scope was to produce the 3D models according to the specifications set by the project and, most importantly, within the available time frame, which was highly restricted due to the COVID-19 pandemic. The size and heterogeneity of all data acquired and produced require special management and maintenance. The system proposed by Petrovic et al. (2014) for the direct visualization and analysis of such data, allowing the different aspects recorded to be layered together, and covisualized with annotations and other relevant information, is of great interest.

\subsection{Fieldwork - Data Acquisition}

The field work for the data acquisition lasted six (6) days, took place in June 2020 and was performed by a team of six members from the Laboratory of Photogrammetry and one from the Laboratory of Remote Sensing of National Technical University of Athens (Figure 3). The team was split in two sub-teams working simultaneously and assisting each other when necessary. This required careful and accurate planning of work and coordination of those who participated in the field work, for the most efficient use of the available equipment and proper time management.

Digital high-resolution images were acquired in different ways according to the size, complexity and level of detail of each monument using high resolution full-frame cameras either handheld or with a 9-meter-high photographic pole. In addition, UAV images of lower resolution were also acquired to complete the $3 \mathrm{D}$ models from above.

Furthermore, terrestrial laser scanning has been conducted to accurately determine the surface of the cultural heritage buildings used as reference for the routine and post-disaster monitoring, as foreseen by the research project. Two terrestrial laser scanners, a Leica BLK360 and a FARO HDR, were employed to speed-up the process, but also to provide completeness to the point clouds.

A local reference coordinate system was set up at each cultural heritage building area, thus establishing the necessary control points. For the geodetic measurements two total stations were used and the coordinates of the required points, such as targets for the point cloud registration and ground control points for the orientation of images were determined. This was important because the georeferencing of heterogeneous data in the same reference system ensures their use for the production of the requested products with the required specifications. Georeferencing of the measurements to the Greek reference System (GGRS87) was not required.

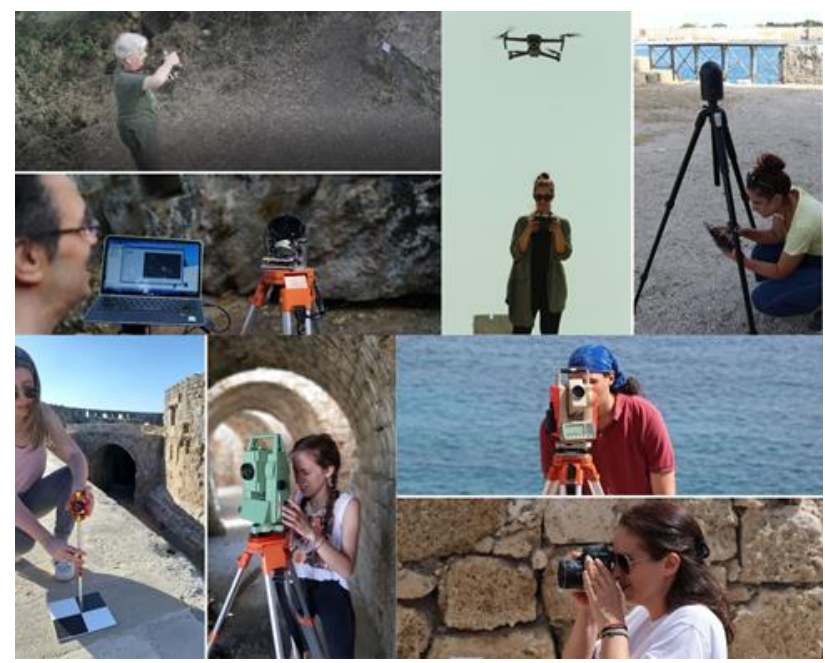

Figure 3. Field work for the data acquisition.

In addition, close-range hyperspectral data were acquired at particular selected parts of the four cultural heritage buildings in order to extract, identify and assess material features and degradation on these buildings. (Kolokoussis et al. 2021). A summary of the acquired data is given in Table 1.

\begin{tabular}{|l|c|c|c|}
\hline $\begin{array}{c}\text { Cultural } \\
\text { Heritage Site }\end{array}$ & $\begin{array}{c}\text { Number of } \\
\text { Aerial } \\
\text { Images }\end{array}$ & $\begin{array}{c}\text { Number of } \\
\text { Ground } \\
\text { Images }\end{array}$ & $\begin{array}{c}\text { Number of } \\
\text { Scans } \\
\text { (Raw file } \\
\text { size })\end{array}$ \\
\hline $\begin{array}{l}\text { Saint Nikolaos } \\
\text { Fort and } \\
\text { lighthouse }\end{array}$ & 1439 & 30 & $\begin{array}{c}69 \\
(15,8 \mathrm{~GB})\end{array}$ \\
\hline Naillac Pier & 1117 & 736 & $\begin{array}{c}38 \\
(5,4 \mathrm{~GB})\end{array}$ \\
\hline Roman Bridge & 2576 & 271 & $\begin{array}{c}24 \\
(5,8 \mathrm{~GB})\end{array}$ \\
\hline Rhodini & 492 & 779 & $\begin{array}{c}41 \\
(10 \mathrm{~GB})\end{array}$ \\
\hline
\end{tabular}

Table 1. Summary of acquired data.

\subsection{Data Processing and Results}

Data processing was performed in two phases, during fieldwork in Rhodes (in situ) and after returning to Athens (in office). The first phase was very important for ensuring that no data was omitted. All necessary network calculations and adjustments, as well as the determination of final point coordinates were carried out in situ to ensure that all points were measured and their coordinates were correct, but also to ensure that the specified accuracy was achieved. Pre-processing of point clouds and imagery, without georeferencing, was performed also in situ i.e. all point clouds from laser scanning were pre-registered and all acquired images were oriented with low accuracy, in order to ensure that there was no lack of data and to repeat additional scans or shooting, if necessary (Figure 4). 


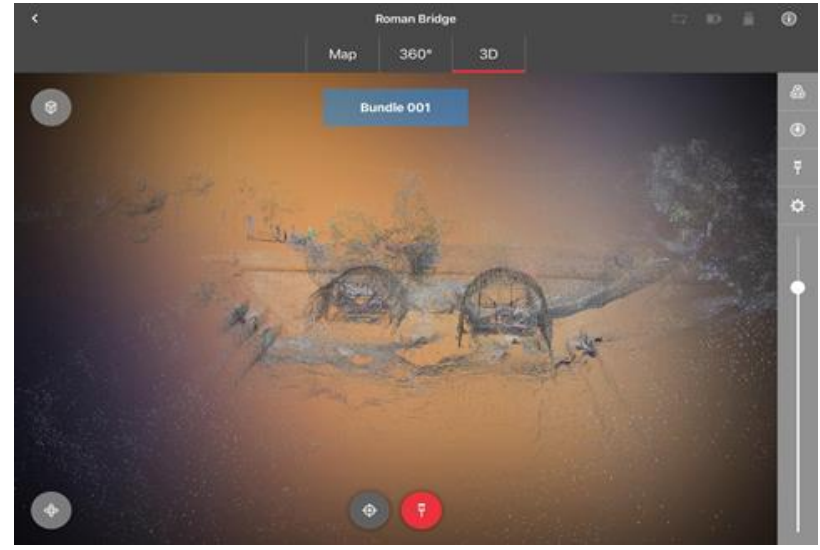

Figure 4. In-situ pre-registration of the scans.

Proper processing was conducted later, in the office, following the standard workflow shown in figure 5 and discussed in the next paragraphs.

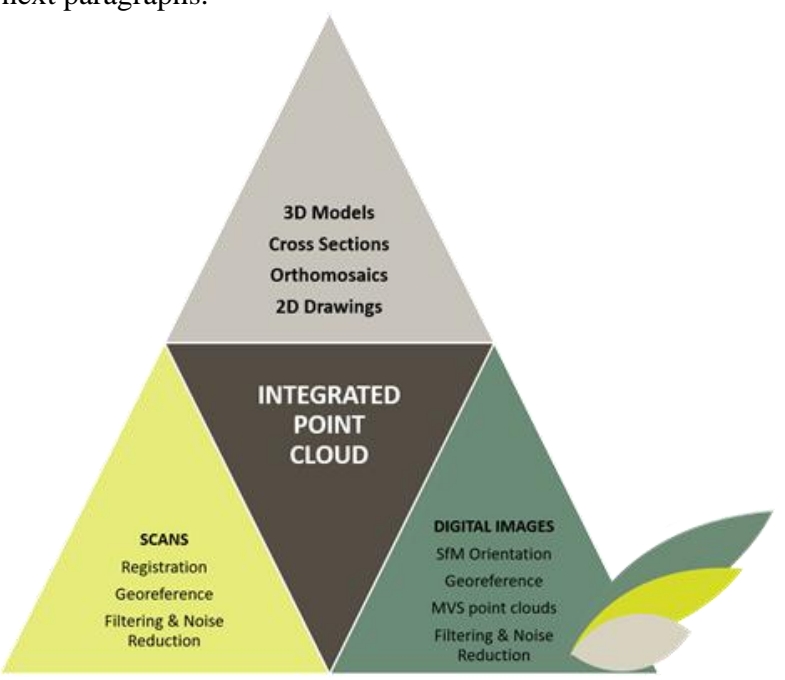

Figure 5. The workflow of data processing.

At first all the acquired images were oriented once again with high accuracy via the automated Structure from Motion (SfM) process (Figure 6). The aerial images acquired with the UAS were separately processed from the ground images since they were of lower resolution. The research and experience of the laboratory of Photogrammetry and the engagement with the geometric documentation of multiple cultural heritage objects, where the SfM method is now applied, has led to the conclusion that special emphasis should be given to the successful completion of this stage. This stage, called 'alignment' very often, is actually the relative orientation of the images, aiming, among others, at the creation of the correct shape of the object. Therefore it is important to ensure that all tie points, which are often called "sparse cloud", are correct. To achieve this, all available optimization tools must be used and applied. After the successful orientation, the datasets were georeferenced by detecting the targets and introducing the coordinates. The georeferencing accuracy of the oriented images in each cultural heritage building was less than $1.2 \mathrm{~cm}$. The next step was the production of the dense point clouds using the Multi-View Stereo (MVS) reconstruction algorithms. The point clouds were further processed in order to remove noise and unnecessary or inaccurate points, while a more uniform point cloud was produced.

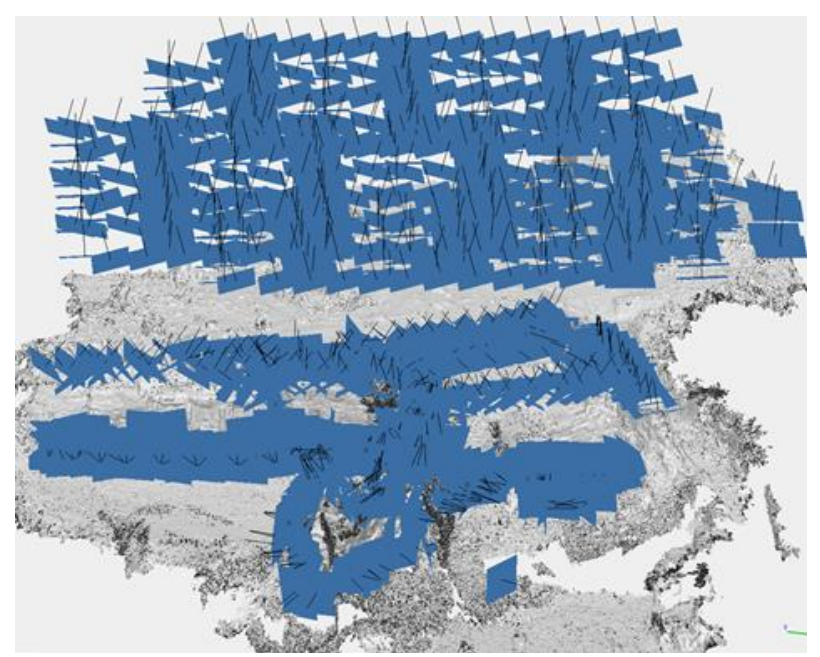

Figure 6. The position of the oriented cameras at the Rhodini.

Then the scanned point clouds were registered by applying the Cloud-to-Cloud method employing the Iterative Closest Point (ICP) algorithm algorithm, due to the sufficient overlap between the scans. ICP is one of the popular approaches in spatial registration-based methods (Besl \& McKay, 1992). The optimized, registered scans were georeferenced by setting the coordinates to the identified targets. The georeferencing accuracy of the registered scanned point clouds was less than $1 \mathrm{~cm}$.

The final integrated point cloud was produced mostly by exploiting the scanned point clouds, while the MVS point clouds were used only to fill gaps. It is important to mention that it is recommended to use mainly the scanner point clouds and not the MVS point clouds because the processing of the former is much easier and more efficient than the latter. This is mainly due to the fact that there is less noise in the scanner point clouds compared to MVS point clouds, resulting in surfaces much closer to the real ones after processing.

The point cloud of each cultural heritage building will be integrated into the HRAP Platform and be used as reference for the routine and post-disaster monitoring after every 3D documentation to perform comparisons and evaluations of the deviation during the years.

The creation of the integrated and accurate 3D models was imperative, because these models were used for the production of all other necessary products (Figure 7). It is advantageous to convert a point object to a polygon object because there are many refinements that can be performed on a polygon object which cannot be performed on a point object. For the representation of the continuous surfaces, the triangulated irregular network (TIN) was chosen, because it is a simple way to build a surface from a set of irregularly spaced points. In areas where the surface is smooth, the points may be at a greater distance, while in areas with more intense relief the density of the points increases. This reduces the number of points and hence the number of triangles required for modeling complex surfaces and, consequently, the size of the file. Also, TINs are able to be stored in various file formats and be used in a variety of software for further 3D processing, analysis and production of different products, such as cross-sections, contours, raster DSMs, textures, orthomosaics etc.

The detailed 3D textured models, of particular selected parts of the four cultural heritage buildings, were needed for the 
extraction, identification and assessment of material features and degradation on these buildings, as described in Kolokousis et al (2021). The careful application of the texture from the oriented RGB and Hyperspectral images, completed the detailed 3D textured models (Figure 8).

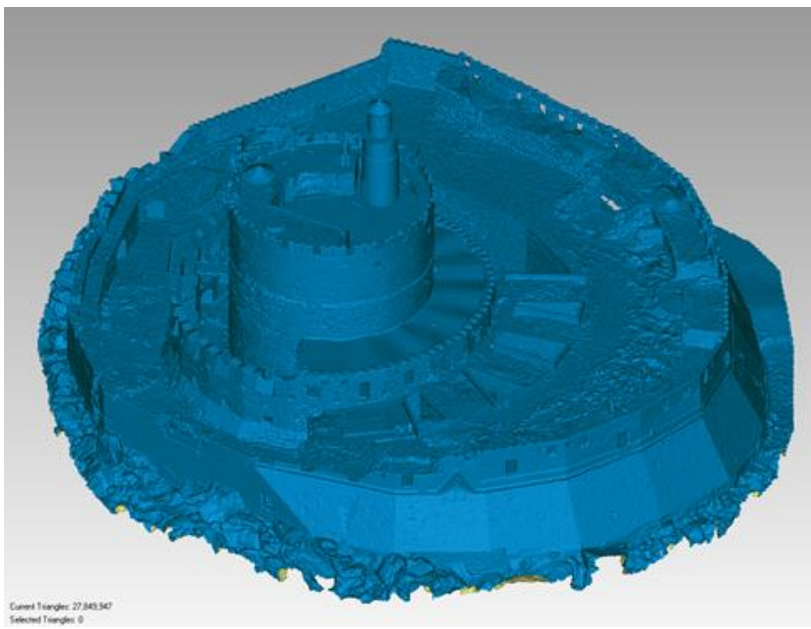

Figure 7. The integrated 3D model of the Saint Nikolaos Fort and lighthouse.

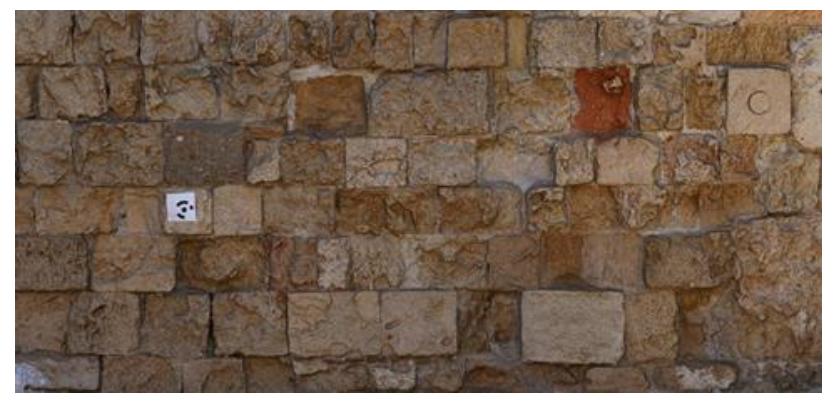

Figure 8: Detailed Textured 3D Model.

In order to produce the light 3D models (Figure 9) for visualisation purposes, the decimation of the detailed models was necessary. This decimation was performed according to the complexity of each cultural heritage building, in order to keep the main geometry, shape and important details. This procedure enables the reduction of the number of triangles in the mesh of an object without compromising surface detail or colour. It is important to keep more triangles in the curved regions, to allow for the correct appearance of a complex surface while the details of the curved regions are maintained.

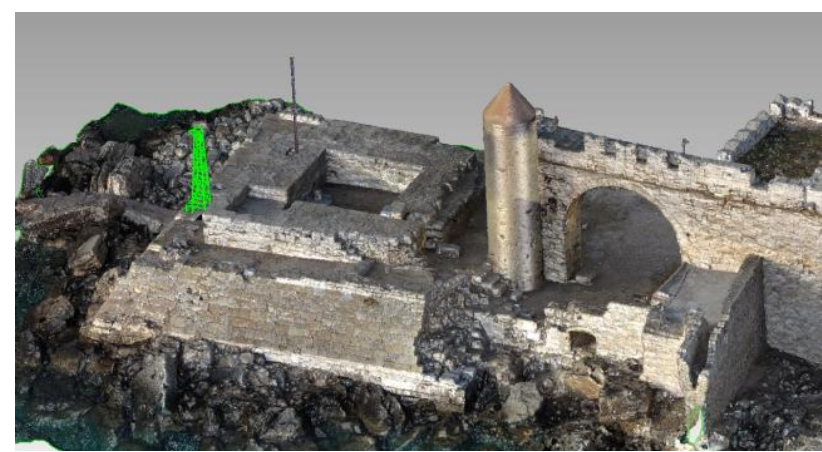

Figure 9: The light 3D Model of the Naillac Pier.
Additionally, cross-sections at positions every $6 \mathrm{~cm}$ and $30 \mathrm{~cm}$, according to the requirements, were produced to support the creation of the appropriate models for the finite elements method (FEM) and analysis. (Figure 10)

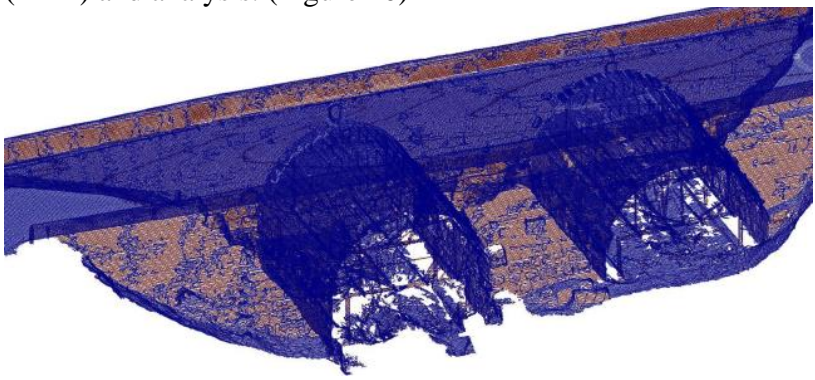

Figure 10: The cross-sections at $6 \mathrm{~cm}$ intervals of the Roman Bridge.

Finally, the detailed models were used for the production of traditional 2D drawings and orthomosaics, to support structural studies of the archaeologists in charge.

\section{CONCLUDING REMARKS}

The need to create and establish a holistic framework for the documentation of Cultural Heritage is rising rapidly in the last decades. This framework integrates the conduct of a wide range of interdisciplinary research, acquisition and combination of data sets from various sensors and sources, as well as the development of innovative tools for systematic monitoring. Therefore, this multi-disciplinary process is able to give substantial results for the protection, preservation and enhancement of Cultural Heritage sites.

The 3D geometric documentation of the four cultural heritage buildings in Rhodes was carried out in order to produce and prepare all the required and specified products for the HYPERION project. The methodology applied ensured the achievement of these specifications in terms of accuracy and resolution. These products have provided all the necessary information and data for the scientists working towards the HYPERION Information System, called HRAP. HRAP aims to integrate all the hazard and impact assessment tools and modelling data in order to support decisions at strategic, tactical and operational level.

It has been shown that employing contemporary digital multi source data acquisition techniques the best possible 3D results for the geometric documentation can be achieved. This by a minimum number of personnel and relatively low-cost instrumentation. Care should be given to (i) the completeness of the data acquired in the field and (ii) the careful processing by exploiting the best information from each dataset. For example, the 3D surface of the objects, especially in cases of highly complex geometry, should be described by an optimal number of triangles carefully produced from the data acquired. Involved experts should have good knowledge of the object and be aware of the many pitfalls and blunders produced by the automated software. Unfortunately, automation may seemingly produce "nice" results, but deep down they might very often be wrong. In addition, one should master and understand the various parameters offered to the users by the software, in order to achieve the best possible results from the data available. This skill requires patience and study by trial and error combined with deep knowledge of Photogrammetry and Computer Vision. 


\section{ACKNOWLEDGEMENTS}

This work is part of the HYPERION project. HYPERION has received funding from the European Union's Framework Programme for Research and Innovation (Horizon 2020) under grant agreement no. 821054. The content of this publication is the sole responsibility of NTUA (Work Package 6, Task 6.3) and does not necessarily reflect the opinion of the European Union. For all figures permissions have been obtained from the owners.

\section{REFERENCES}

Anastasiou, A., Syrokou, E., Tapinaki, S., Georgopoulos, A., 2020. HOLISTIC 3D DIGITAL DOCUMENTATION OF A BYZANTINE CHURCH, Int. Arch. Photogramm. Remote Sens. Spatial Inf. Sci., XLIII-B2-2020, 1363-1370. doi.org/10.5194/isprs-archives-XLIII-B2-2020-1363-2020.

Bariami, G., Faka, M., Georgopoulos, A., Ioannides, M. Skarlatos D., 2012. "Documenting a UNESCO WH site in Cyprus with complementary techniques", International Journal of Heritage in the Digital Era, vol. 1, pp. 27-32, 2012. https://www.cut.ac.cy/euromed2012proceedings/shortPapers/27. pdf. $(29 / 6 / 2021)$

Besl, P. J., McKay, N. D., 1992. "A method for registration of 3 D shapes," in IEEE Transactions on Pattern Analysis and Machine Intelligence, vol. 14, no. 2, pp. 239-256, Feb. 1992. doi.org/10.1109/34.121791.

Georgopoulos, A., Ioannidis, Ch., Soile, S., Tapinaki, S., Chliverou, R., Tsilimantou, E., Lampropoulos, K., Moropoulou, A., 2018. The Role of Digital Geometric Documentation for the Rehabilitation of the Tomb of Christ. In: A. C. Addison \& H. Thwaites (Editors), Proceedings of the 2018 3rd Digital Heritage International Congress (DigitalHERITAGE) held jointly with the 2018 24th International Conference on Virtual Systems \& Multimedia (VSMM 2018), 26-30 October 2018, San Francisco, USA, IEEE Catalog Number: CFP1808W-ART ISBN 978-17281-2002-7. doi.org/10.1109/DigitalHeritage.2018.8810044

Georgopoulos A., Skamantzari M., Tapinaki S., 2020. Digitally Developing Medieval Fortifications, FORTMED2020 International Conference on Fortifications of the Mediterranean Coast, Defensive Architecture of the Mediterranean / Vol X / Navarro Palazón, García-Pulido (eds.). doi.org/10.4995/FORTMED2020.2020.11468.

Google Arts \& Culture, ONLINE EXHIBIT: Hidden Heritage Under Threat: Lavrio Historic Wharf, ICOMOS - International Council on Monuments and Sites https://artsandculture.google.com/exhibit/hidden-heritageunder-threat-lavrio-historic-wharf/6wLCmavIkVL6JA $(29 / 6 / 2021)$

Hess M., Petrovic V., Meyer D., Rissolo D., Kuester F., 2015. "Fusion of multimodal three-dimensional data for comprehensive digital documentation of cultural heritage sites," 2015 Digital Heritage, Granada, Spain, 2015, pp. 595-602. doi.org/10.1109/DigitalHeritage.2015.7419578.

http://digiphotolab.survey.ntua.gr/, The official website of the Laboratory of Photogrammetry, School of Rural, Surveying and Geoinformatics Engineering, National Technical University of Athens (29/6/2021) https://www.hyperion-project.eu/, Hyperion project's official website $(29 / 6 / 2021)$

HYPERION Deliverable 2.1, 2021: https://www.hyperionproject.eu/ (29/6/2021)

Kolokoussis P., Skamantzari M., Tapinaki S., Karathanassi V., Georgopoulos A., 2021. "3D and Hyperspectral Data Integration for Assessing Material Degradation in Medieval Masonry Heritage Buildings", XXIV ISPRS Congress, Commission II, WGII/8, 4-10 July 2021, Nice, France. doi.org/10.5194/isprsarchives-XLIII-B2-2021-583-2021.

Kotoula, L., Georgopoulos, A., 2015. Digital Documentation for the Restoration of the Anargyros Mansion Proceedings 2nd International Congress on Digital Heritage 2015, Granada 28.0902.10.2015, pp. 731-734, ISBN 978-1-5090-0254-2. doi.org/10.1109/DigitalHeritage.2015.7419610.

Kouimtzoglou, T., Stathopoulou, E. K., Agrafiotis, P., Georgopoulos, A., 2017. Image-based 3D reconstruction data as an analysis and documentation tool for architects: the case of Plaka Bridge in Greece. Int. Arch. Photogramm. Remote Sens. Spatial Inf. Sci., XLII-2/W3, 391-397. doi.org/10.5194/isprsarchives-XLII-2-W3-391-2017, 2017.

Manousou Ntella K., 2017. The Medieval City of Rhodes, works of restoration (2011 - 2016), Supervisory Committee for work on the monuments of the mediaeval city of Rhodes, Ministry of Culture, Rhodes 2017.

Moropoulou, A., Georgopoulos, A., Korres, M., Bakolas, A., Labropoulos, K., Agrafiotis, P., Delegou, E., Moundoulas, P., Apostolopoulou, M., Lambrou, E., Pantazis, G., Kotoula, L., Papadaki, A., Alexakis, E., 2017. Five-Dimensional (5D) Modelling of the Holy Aedicule of the Church of the Holy Sepulchre Through an Innovative and Interdisciplinary Approach. In: Ioannides M., Magnenat-Thalmann N., Papagiannakis G. (eds) Mixed Reality and Gamification for Cultural Heritage. Springer, Cham. doi.org/10.1007/978-3-31949607-8_9.

Petrovic V., Vanoni D. J., Richter A. M., Levy T. E. and Kuester F., 2014. "Visualizing high resolution three-dimensional and two-dimensional data of cultural heritage sites", Mediterranean Archaeology and Archaeometry, vol. 14, no. 4, pp. 93-100, 2014. https://escholarship.org/uc/item/58z4j8k2 (29/6/2021)

Stathopoulou, E. K., Georgopoulos, A., Panagiotopoulos, G., and Kaliampakos, D., 2015. Crowdsourcing Lost Cultural Heritage. ISPRS Ann. Photogramm. Remote Sens. Spatial Inf. Sci., II5/W3, 295-300. doi.org/10.5194/isprsannals-II-5-W3-295-2015.

Tsilimantou, E., Delegou, E., Bourexis, F., Tapeinaki, S., Soile, S., Ioannidis, C., Moropoulou, A., 2019. Combination of Geometric Documentation and Infrared Thermography Results for Preservation Purposes in Archaeological Sites. In: Osman A., Moropoulou A. (eds) Nondestructive Evaluation and Monitoring Technologies, Documentation, Diagnosis and Preservation of Cultural Heritage. Springer Proceedings in Materials. Springer, Cham. doi.org/10.1007/978-3-030-25763-7_16. 